\title{
Follow-up care of women with an abnormal cytology in a low-resource setting
}

\author{
Julia C. Gage, $\mathrm{MPH}^{\mathrm{a}, *}$, Catterina Ferreccio, MD, MPH ${ }^{\mathrm{b}}$, Miguel Gonzales, $\mathrm{MD}^{\mathrm{c}}$, \\ Raul Arroyo, $\mathrm{MD}^{\mathrm{d}}$, Militza Huivín ${ }^{\mathrm{d}}$, Sylvia C. Robles, MD, MSc ${ }^{\mathrm{e}}$ \\ ${ }^{a}$ Health Resources and Services Administration, 5600 Fishers Lane, Room 18-41, Rockville, MD, USA \\ ${ }^{\mathrm{b}}$ Departamento de Salud Pública, Pontificia Universidad Católica de Chilé, Santiago, Chile \\ ${ }^{\mathrm{c}}$ Proyecto TATI, San Martín, Perú \\ ${ }^{d}$ Dirección Regional de Salud de San Martín, Perú \\ ${ }^{\mathrm{e}}$ Division on Non Communicable Diseases, Pan American Health Organization, Washington, DC, USA
}

Accepted 10 September 2003

\begin{abstract}
Study purpose: We ascertained the follow-up care after an abnormal cytology (Papanicolaou) screening in the San Martín region of Perú and assessed the status of women who had not received adequate care. Basic procedures: We identified women with an abnormal cytology and assessed their medical records, laboratory registries, death certificates and interviewed them at home. Re-screening, diagnosis and treatment were offered. Main findings: Only $46(25 \%)$ of the 183 women identified received appropriate follow-up care. At re-screening 31 (34\%) had a normal result, 9 (10\%) were diagnosed with CIN1 and 50 (56\%) had CIN2 or worse. Principal conclusions: In this setting, follow-up care after an abnormal cytology was very poor and could explain the lack of impact of cervical cancer screening. Women with an abnormal cytology constitute a high-risk group that should be a priority for health services.
\end{abstract}

(C) 2003 International Society for Preventive Oncology. Published by Elsevier Ltd. All rights reserved.

Keywords: Cervix neoplasms/prevention and control; Developing countries; Cervical intraepithelial neoplasia/prevention and control; Vaginal smears; Mass screening; Peru

\section{Introduction}

Screening programs to detect precancerous lesions on the cervix using conventional cytology (Papanicolaou) have been successful in reducing overall mortality in developed countries [1]. Yet, many middle-income developing countries have found that even after offering cytology-based screening, it has been difficult to reduce mortality due to cervical cancer [2]. Screening programs are susceptible to technical, logistical and programmatic barriers such as poor participation, lack of organization, inadequate diagnostic and treatment measures and poor follow-up of detected abnormalities. A recent case control study in Lima, Perú found that having had at least three lifetime cytology smears was not significantly associated with a reduction in risk of cervical cancer [3]. San Martín is a low-resource region

* Corresponding author. Tel.: +1-301-443-0701; fax: +1-301-443-2268. E-mail address: jgage@hrsa.gov (J.C. Gage). in Perú that has used the organized regional public health system to offer cytology-based cervical cancer screening. While the incidence of cervical cancer in San Martín is unknown, two cancer registries in Perú have reported an age adjusted incidence rate of cervical cancer of 53.5 per 100,000 in Trujillo between 1988 and 1990 and 27.3 per 100,000 in Lima between 1990 and 1993 [4].

Given that adherence in this setting had never been documented, the aim of this study was to measure the completeness of subsequent diagnosis and treatment among women with an abnormal cytology in San Martín and assess the status of women who had not received adequate follow-up care.

\section{Materials and methods}

The San Martín province is located in the Amazonian region and had 769,331 inhabitants in 1999, of whom $43 \%$ 
live in poverty and $37 \%$ in a rural area. The region has 4.3 doctors per 10,000 inhabitants [5]. Approximately $9 \%$ of the inhabitants of the area are indigenous from the Aguarunas, Chayahuitas and Lamas-Chachapoyas groups. One-quarter (26\%) of women 30 years or older have four or more children [6].

Through collaboration with the local health department, we obtained information regarding diagnosis, treatment and disease progression that occurred 6-21 months after the initial abnormal cytology by systematically reviewing medical records from public hospitals and outpatient clinics, laboratory registries, death certificates and the National cancer hospital in Lima. Local midwives conducted home interviews with patients or family members, exploring whether patients knew their Pap result, the type of follow-up care received and reasons for not attending. Women were offered re-screening, diagnosis and treatment as needed at the study clinic with transport and lodging provided by the study. Informed consent was obtained. Further care or treatment was confirmed through the medical record; however, if this was not available, self-reports of treatment and reports by a family member of death were accepted at face value. If none of the above were available, the woman was considered "not identified." Data on patient information were entered into an MS ACCESS database. The analysis for this paper was generated using SAS software [7]. We calculated chi-square statistics to determine the significance of the difference between women identified and those for which no information was available other than having had a positive cytology.

\section{Results}

\subsection{Identification of the study population}

Between January 1999 and April 2000, 6 months before initiation of this study, 40,369 smears were taken from women 13-75 years old (average 28 years). Conventional cytology detection rate of any abnormality was $1 \%$ (four atypical squamous cells of undetermined significance (ASCUS), 122 low-grade squamous intraepithelial lesion (LSIL), 153 high-grade squamous intraepithelial lesion (HSIL) and 31 carcinoma). A review of cytology registries revealed that these 310 abnormal smears corresponded to 243 women as 22 women had more than one smear. Of these 243 women, 10 were excluded from our study because they resided more than a 1-day travel from a health center $(n=9)$ or had a previous hysterectomy $(n=1)$ (Fig. 1). The remaining 233 women were included in our target population with the following cytology results: 4 (1.7\%) ASCUS, 92 (39.5\%) cervical intraepithelial neoplasia grade 1 (CIN1), 68 (29.2\%) cervical intraepithelial neoplasia grade 2 (CIN2), 48 (20.6\%) cervical intraepithelial neoplasia grade 3 (CIN3) and 21 (9.0\%) carcinoma.

Our search identified 197 of 233 women in the target population (85\%). The index Pap of the 197 women identified was comparable to that of the total target (1.5\% ASCUS, $40.6 \%$ CIN1, 27.4\% CIN2, 21.3\% CIN3 and 9.1\% carcinoma). The mean age was 34 years (range 15-77) and the average age of initiation of sexual relations was 16.3 years. The majority of women were married or lived with a

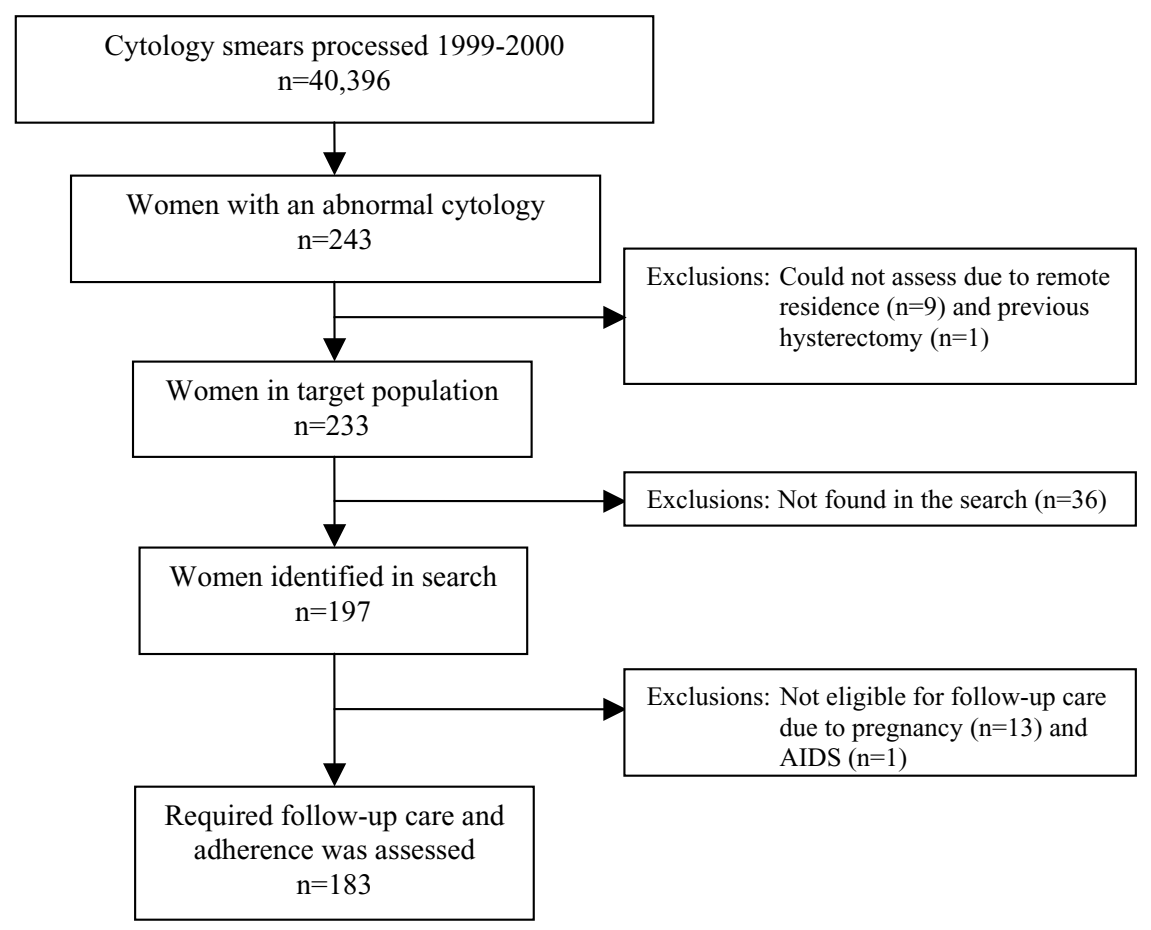

Fig. 1. Identification of the study population for assessment. 
domestic partner (88\%) and had attended elementary school or higher $(89 \%)$. These characteristics were not statistically different from those of the 36 women not identified.

Altogether, 14 women required a different management, 13 due to pregnancy and 1 because she was HIV positive (Fig. 1). We did not ascertain diagnosis and treatment status in these women; therefore our study population consisted of 183 women.

\subsection{Follow-up care and subsequent health status}

Of the 183 women who required follow-up care; 63 (34\%) received a biopsy, $32(18 \%)$ only had a second cytology (although biopsy was indicated for at least 11 women as their index cytology was CIN2 or worse) and 88 (48\%) did not receive medical care (Table 1 ).

Histology confirmed a CIN2 lesion or greater in 46 (73\%) of the 63 women who had received a biopsy (Fig. 2). Among these 46 women with histological diagnosis of CIN2 or worse, $17(37 \%)$ were untreated and $11(24 \%)$ received treatment consisting of cold conization for CIN3, radiotherapy for invasive or epidermal carcinoma and hysterectomy for epidermal carcinoma (Table 2). Up to 18 (39\%) women
Table 1

Assessment of follow-up examination 6-22 months after abnormal cytology

\begin{tabular}{lrccc}
\hline Index cytology & Total & \multicolumn{3}{c}{ Examination received $^{\mathrm{a}}$} \\
\cline { 3 - 5 } & & None & Cytology & Biopsy \\
\hline ASCUS & 3 & 2 & 0 & 1 \\
CIN1 & 70 & 38 & 21 & 11 \\
CIN2 & 48 & 22 & 7 & 19 \\
CIN3 & 44 & 17 & 3 & 24 \\
Carcinoma & 18 & 9 & 1 & 8 \\
Total & 183 & 88 & 32 & 63 \\
\hline
\end{tabular}

${ }^{\mathrm{a}}$ Highest follow-up examination.

Table 2

Assessment of treatment received after a biopsy CIN2 or worse

\begin{tabular}{|c|c|c|c|c|c|}
\hline \multirow{2}{*}{$\begin{array}{l}\text { Lesion } \\
\text { type }\end{array}$} & \multirow[t]{2}{*}{ Total } & \multicolumn{3}{|c|}{ Treatment received } & \multirow{2}{*}{$\begin{array}{l}\text { Any } \\
\text { treatment } \\
(\%)\end{array}$} \\
\hline & & $\begin{array}{l}\text { No } \\
\text { treatment }\end{array}$ & Ambulatory & $\begin{array}{l}\text { Hysterectomy } \\
\text { or radiotherapy }\end{array}$ & \\
\hline CIN2 & 8 & 5 & 0 & 3 & 33.3 \\
\hline CIN3 & 21 & 4 & 2 & 15 & 81.0 \\
\hline Carcinoma & 17 & 8 & 0 & 9 & 52.9 \\
\hline Total & 46 & 17 & 2 & 27 & 63.0 \\
\hline
\end{tabular}

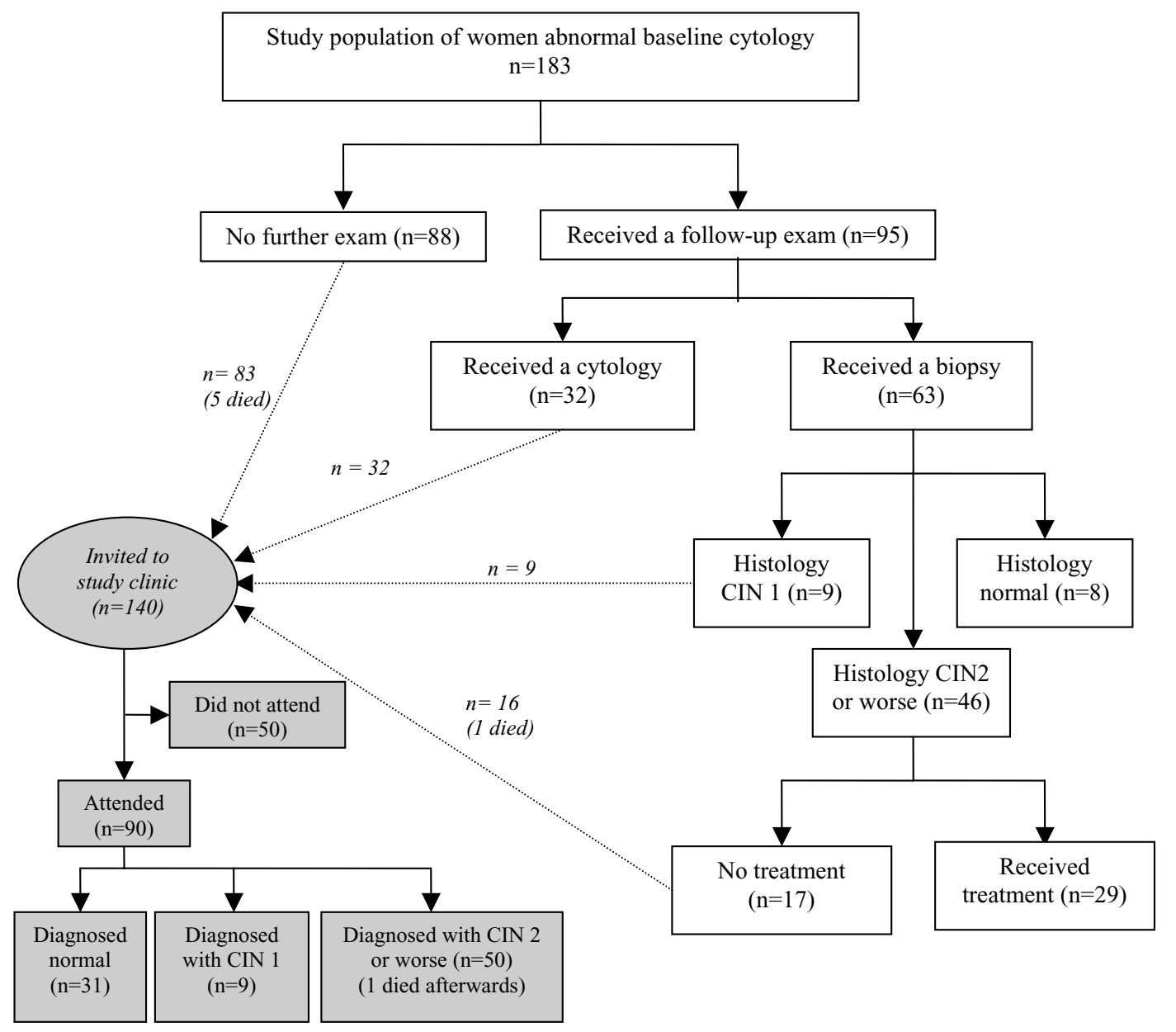

Fig. 2. Assessment of adherence with follow-up care after an abnormal cytology. 
could have been over-treated as they received a hysterectomy for a CIN2 or CIN3 grade lesion.

We invited for new screening 131 women who were still alive and had insufficient follow-up care and 9 women who had CIN1 diagnosis upon histology (Fig. 2). Of these 140 women, $90(64 \%)$ attended. Upon re-examination 7-22 months (12.5 median) after their index cytology, 10 women (11\%) had a normal cytology, 21 (23\%) were confirmed as normal on colposcopy or histology, $9(10 \%)$ women had a CIN1 result, while $50(56 \%)$ presented CIN2 or worse (12 of which were invasive cancer and 1 died soon afterwards).

In total, six (3\%) women had already died of carcinoma of the cervix when this assessment began while one more (1\%) died soon after re-screening at the study clinic. Of these women who died, one had an index cytology result of CIN2, two had CIN3 and four had carcinoma.

\section{Discussion}

In 1999, conventional cytology screening was offered to all women of reproductive age seeking medical attention in the health system throughout the San Martín region (opportunistic screening). Smears were processed in one of seven laboratories throughout the region without an organized quality control system. Women had to return to the health establishment for their results. Occasionally health workers visited patients' homes to inform them of abnormal results. No systematic educational message was given to women when their results were abnormal and many did not recall any messages regarding follow-up. Peruvian guidelines recommend that women with abnormal cytology receive a biopsy. The region had one colposcopy unit in a private practice. When taken, histology samples were sent to Lima (1-h flight of $739 \mathrm{~km}$ ), and results were received up to 4-5 months later. If the biopsy confirmed a high-grade lesion, the patient was referred to the public hospital in Tarapoto to receive a total hysterectomy; women with invasive cancer were transferred to the public hospital in Lima $(1500 \mathrm{~km}$ by land). To obtain diagnosis and treatment services women had to pay a co-payment that, while small, was beyond reach for most patients.

Following national Peruvian guidelines that all patients with a cytology result of ASCUS, CIN1 or worse receive histology, $34 \%$ of all patients received appropriate diagnostic evaluation. Peruvian guidelines also state that all patients with a histology result of CIN2 or worse should receive treatment; accordingly, adherence with both diagnosis and treatment was $25 \%$ (Fig. 1).

Overall cytology screening results showed an unexpected low detection rate of any abnormality (1\%) that was 3-4 times lower than the common detection rate in Latin America [8]. In addition, fewer ASCUS and CIN1 results (4 and 122) were reported than CIN2 or worse results (153), suggesting that either the quality of cytology-processing is poor or cytology is used primarily for diagnosis. To ensure ad- equate skills, it is recommended that between 20,000 and 30,000 cytology smears be processed annually in a laboratory [1]. During 1999, seven laboratories processed around 30,000 smears, suggesting that the quality of analysis in regional laboratories is inadequate. In 2000, this problem was addressed when all smears were sent to one reference laboratory for examination. Studies have found that the conventional cytology test has a 30-87\% sensitivity (mean, 47\%) to detect high grade lesions and a $86-100 \%$ specificity [9]. Similar results have been reported in low-resource settings [10]. In our study $45 \%$ of women with a CIN 1 cytology and $64 \%$ of women with HSIL had a subsequent histological diagnosis of CIN3 or cancer. These high estimated predictive values and unexpected results of cytology screening suggest that in this setting, and similar ones where cytologists are most likely inexperienced or poorly trained and a quality control system is not in place, any abnormal cytology result including CIN1 should prompt action.

We reviewed published studies that measured adherence with all recommended follow-up procedures after an abnormal cytology and identified 17 published between 1992 and 2001 that examined between 62 and 14,300 women each [11-27]. Most studies sought to ascertain reasons for low patient response to notifications of results or missed follow-up appointments and determine the influence of interventions on adherence. Unlike our review, five studies were prospective in evaluating intervention strategies or screening programs. Although all most all studies reviewed medical records to ascertain adherence, only eight of them contacted patients either by phone or through home visits to verify non-adherence $[11,13,14,16,18,19,23,25]$. Our study was most similar to six of the identified studies in that they evaluated adherence with all recommended follow-up procedures, conducted record review and contacted patients $[11,13,14,18,19,25]$. We ascertained the follow-up and health status of $85 \%$ of the women, a percent comparable with these five studies (60-96\%). These six studies reported between 62 and $71 \%$ adherence, a figure much higher than in Perú $(25 \%)$.

Only one other published study was conducted in a less developed country. In Thailand, authors cite a $67 \%$ adherence rate and attribute poor adherence to inadequate communication of results or travel-related reasons [25]. Our study found considerably lower adherence in the San Martín region of Perú $(25 \%)$. One explanation for this difference is that the other study was conducted at a large urban outpatient unit of the hospital OB/GYN department at Srinagarind Hospital in Khon Kaen City. Comparatively, in San Martín only $11 \%$ of women attended one of the two main hospitals in the region, while $65 \%$ attended a health center or rural hospital and $24 \%$ attended a rural health post (data not shown). Adherence in this setting was dependent upon patient referral to a main public hospital where diagnostic and treatment methods are available.

When women reached a main hospital and were diagnosed with abnormal lesions, they were more likely to 
undergo hysterectomy because safer, less-expensive, lowtechnology methods were not available. Various authors have reported similar over-treatment for pre-cancerous lesions of the cervix in other less developed countries and identified the need for appropriate medical care infrastructure and resources to allow for preference to conservative treatment $[1,10,28]$. A survey of clinicians specializing in women's health and public health, found that hysterectomy and cone biopsy were used more widely worldwide than alternative methods to treat CIN and most often gynecologists, rather than other clinical personnel, treated patients [28]. Authors have also called to attention the need for appropriate medical care infrastructure and resources to guarantee appropriate diagnosis and preference to conservative treatment in less developed countries [2,10,28].

While adherence should be strived for, we should also acknowledge that some patients will not return and that perhaps the alternative of immediate treatment should be offered to the patients at greater risk. Efforts should be made to characterize and identify those women who are less likely to adhere. Although not statistically significant, in our series, the 19 women who did not attend re-screening were older (average age 37.5 versus 32.9 years, $P>.05$ ) and had more children (average parity 4.7 and 3.7 children, $P>.05$ ) than the 121 women who attended.

Our study was subject to bias in that not all women were identified because many moved out of the region and could not be contacted in their new residence. In the best scenario where all 36 missing women received all follow-up care, adherence would be underestimated by $20 \%$, i.e. the true adherence would be $45 \%$ instead of $25 \%$ (following Peruvian guidelines). Given the retrospective nature of data collection, the various sources of records could be a cause of error. It is possible that some interventions were not registered and women or family had forgotten follow-up care. Another limitation to the study was the use of local heath department midwives to identify and interview patients. Due to time limitations and the needs of the local health department, the midwives interviewing women and obtaining data were in many cases the same midwives responsible for informing patients of their results and coordinating follow-up. In the surveyor training the non-evaluative nature of the study was explained. They were also offered compensation and were supervised to ensure that all medical records were reviewed and information was complete. It is believed that while the qualitative results from patient interviews are likely to contain significant bias, the quantitative findings of follow-up exams and treatment are reliable.

This case study of the San Martín region is one of the few conducted in a low-resources setting with a close to complete assessment of cases and documents the importance of not only improving screening coverage and quality of screening techniques but also ensuring follow-up diagnosis and treatment. Under these circumstances where infrastructure for follow-up care is poor and the cytology examination is inadequate, if efforts are not made to follow and treat women with all levels of abnormality including CIN1, the incidence of cervical cancer will remain high.

\section{Acknowledgements}

This study was conducted while the first two authors were employed at the Pan American Health Organization and made possible by a grant from the Bill and Melinda Gates Foundation. The authors acknowledge Dr. Merle Lewis for her review of the manuscript and the Women's Health Area coordinators in the San Martín Regional Health Administration (DIRES-SM) and Luzmila Rojas for their assistance in the patient search.

\section{References}

[1] Miller AB, Nazeer S, Fonn S, Brandup-Lukanow A, Rehman R, Cronje $\mathrm{H}$, et al. Report on consensus conference on cervical cancer screening and management. Int J Cancer 2000;86:440-7.

[2] Sankaranarayanan R, Budukh AM, Rajkumar R. Effective screening programmes for cervical cancer in low- and middle-income developing countries. Bull World Health Organ 2001;79:954-62.

[3] Santos C, Munoz N, Klug S, Almonte M, Guerrero I, Alvarez M, et al. HPV types and cofactors causing cervical cancer in Peru. Br J Cancer 2001;85:966-71.

[4] Parkin DM, Whelan SL, Ferlay J, Raymond L, Young J. Cancer incidence in five continents, vol. VII. IARC Scientific Publications No. 143. Lyon, France: International Agency for Research on Cancer; 1997.

[5] Ministerio de Salud, Oficina de Estadística e Informática, Organización Panamericana de Salud del Perú. Situación de Salud en el Perú-Indicadores Básicos. Lima, Perú: El Ministerio de Salud del Perú; 1999.

[6] El Instituto Nacional de Estadística e Informática. Censos nacionales 1993, IX de población, IV de vivienda. Lima, Perú: El Instituto Nacional de Estadística e Informática; 1998.

[7] SAS Institute Inc. SAS Version 6.12 of the $\mathrm{SAS}^{\circledR}$ System for Personal Computers; (c) 1996.

[8] Pan American Health Organization. RedPac Laboratory Performance. Santiago, Chilé; 1999.

[9] Nanda K, McCrory DC, Myers ER, Bastian LA, Hasselblad V, Hickey JD, et al. Accuracy of the Papanicolaou test in screening for and follow-up of cervical cytologic abnormalities: a systematic review. Ann Int Med 2000;132:810-9.

[10] Lazcano-Ponce EC, Moss S, Alonso de Ruiz P, Salmeron Castro J, Hernandez Avila M. Cervical cancer screening in developing countries: why is it ineffective? The case of Mexico. Arch Med Res 1999;30:240-550.

[11] Cardin VA, Grimes RM, Jiang ZD, Pomeroy N, Harrell L, Cano P. Low-income minority women at risk for cervical cancer: a process to improve adherence to follow-up recommendations. Public Health Rep 2001;116:608-16.

[12] Carey P, Gjerdingen DK. Follow-up of abnormal Papanicolaou smears among women of different races. J Fam Pract 1993;37:583-7.

[13] Crane LA. Social support and adherence behavior among women with abnormal Pap smears. J Cancer Educ 1996;11:164-73.

[14] Elwood JM, Cotton RE, Johnson J, Jones GM, Curnow J, Beaver MW. Are patients with abnormal cervical smears adequately managed? Br Med J, Clin Res Ed 1984;289:891-4.

[15] Fox P, Amsberger P, Zhang X. An examination of differential follow-up rates in cervical cancer screening. J Commun Health 1997;22:199-209. 
[16] Funke BL, Nicholson ME. Factors affecting patient compliance among women with abnormal Pap smears. Patient Educ Couns 1993;20:5-15.

[17] Kavanagh AM, Simpson JM. Predicting nonattendance for colposcopy clinic follow-up after referral for an abnormal Pap smear. Aust N Z J Public Health 1996;20:266-71.

[18] Lerman C, Hanjani P, Caputo C, Miller S, Delmoor E, Nolte $\mathrm{S}$, et al. Telephone counseling improves adherence to colposcopy among lower-income minority women. J Clin Oncol 1992;10: 330-3.

[19] Marcus AC, Crane LA, Kaplan CP, Reading AE, Savage E, Gunning $\mathrm{J}$, et al. Improving adherence to screening follow-up among women with abnormal Pap smears: results from a large clinic-based trial of three intervention strategies. Med Care 1992;30:216-30.

[20] Massad LS, Anoina D. Colposcopic and cytologic findings among adolescents referred to two urban teaching hospitals. J Pediatr Adolesc Gynecol 1996;9:190-4.

[21] Michielutte R, Dignan M, Bahnson J, Wells HB. The Forsyth County Cervical Cancer Prevention Project. II. Compliance with screening follow-up of abnormal cervical smears. Health Educ Res 1994;9:42132
[22] Paskett ED, Phillips KC, Miller ME. Improving compliance among women with abnormal Papanicolaou smears. Obstet Gynecol 1995;86:353-9.

[23] Schofield MJ, Sanson-Fisher R, Halpin S, Redman S. Notification and follow-up of Pap test results: current practice and women's preferences. Prev Med 1994;23:276-83.

[24] Stewart DE, Buchegger PM, Lickrish GM, Sierra S. The effect of educational brochures on follow-up compliance in women with abnormal Papanicolaou smears. Obstet Gynecol 1994;83:583-5.

[25] Thinkhamrop J, Lumbiganon P, Jitpakdeebodin S. Loss to follow-up of patients with abnormal Pap smear: magnitude and reasons. J Med Assoc Thai 1998;81:862-5.

[26] Towler BP, Irwig LM, Shelley JM. The adequacy of management of women with CIN2 and CIN3 Pap smear abnormalities. Med J Aust 1993;159:523, 526-528.

[27] Wagner E, Duggan MA. Effectiveness of follow up-letters to health care providers in triggering follow-up for women with abnormal results on Papanicolaou testing. CMAJ 2001;164:207-8.

[28] Bishop A, Sherris J, Tsu VD, Kilbourne-Brook M. Cervical dysplasia treatment: key issues for developing countries. Bull Pan Am Health Organ 1996;30:378-86 